\title{
Use of remote sensing for hydrological parameterisation of Alpine catchments
}

\author{
H. Bach ${ }^{1}$, M. Braun ${ }^{2}$, G. Lampart ${ }^{1}$ and W. Mauser ${ }^{2}$ \\ ${ }^{1}$ VISTA Geowissenschaftliche Fernerkundung GmbH Gabelsbergerstr. 51, D-80333 München, Germany \\ ${ }^{2}$ University of Munich, Department of Earth and Environmental Sciences, Luisenstrasse 37, D-80333 Munich, Germany \\ Email for corresponding author: bach@vista-geo.de
}

\begin{abstract}
Physically-based water balance models require a realistic parameterisation of land surface characteristics of a catchment. Alpine areas are very complex with strong topographically-induced gradients of environmental conditions, which makes the hydrological parameterisation of Alpine catchments difficult. Within a few kilometres the water balance of a region (mountain peak or valley) can differ completely. Hence, remote sensing is invaluable for retrieving hydrologically relevant land surface parameters. The assimilation of the retrieved information into the water balance model PROMET is demonstrated for the Toce basin in Piemonte/Northern Italy. In addition to land use, albedos and leaf area indices were derived from LANDSAT-TM imagery. Runoff, modelled by a water balance approach, agreed well with observations without calibration of the hydrological model.
\end{abstract}

Keywords: PROMET, fuzzy logic based land use classification, albedo, leaf area index

\section{Introduction}

In the EU project RAPHAEL (Runoff and Atmospheric Processes for flood HAzard forEcasting and controL) (Bacchi and Ranzi, 2003), remote sensing methods were used for land surface characterisation of alpine catchments. The basic objective of the RAPHAEL project was to couple meteorological and hydrological models at the regional scale to improve flood forecasting in complex mountain catchments, as in the European Alps. (Fig.1). Numerical Weather Prediction (NWP) is used to forecast precipitation; if it exceeds a warning level, a flood model is initiated. This flood model incorporates information on the hydrological situation of the catchment, including the antecedent moisture conditions from continuous water balance simulations.

The catchment under investigation, the Toce (Piemonte/ Northern Italy, approx. $1500 \mathrm{~km}^{2}$ ), is characterised by extreme topography with elevations ranging from 200 to $4600 \mathrm{~m}$. Corresponding to the strong topographicallyinduced gradient of environmental conditions, the land cover and surface properties are highly variable in space. Hence, for water balance modelling, remote sensing methods were applied to parameterise land surface variables. Land use was classified using a fuzzy logic approach based on a maximum likelihood classification of LANDSAT-TM data. Variables such as albedo and leaf area were also derived from the satellite images. All these remotely sensed variables, in combination with meteorological input and GIS data on elevation and soil, were incorporated in the water and energy balance model PROMET to calculate fluxes, latent heat and evapotranspiration. These simulate the soil moisture dynamics between storms and define the initial state of the system prior to a possible flood.

\section{Remote sensing methods}

\section{PROCESSING OF SATELLITE DATA}

Two LANDSAT-TM images, in spring (May 30th) and autumn (October 16th) 1996, were analysed to estimate surface parameters for the Toce catchment. In the spring image, snow is still prevalent in the upper regions of the catchment, whereas in the autumn image the landscape is snow free, except for glaciated regions. However, the scene in autumn shows strong influence of illumination effects due to the relatively low incidence angle of the sun at this time of the year. 


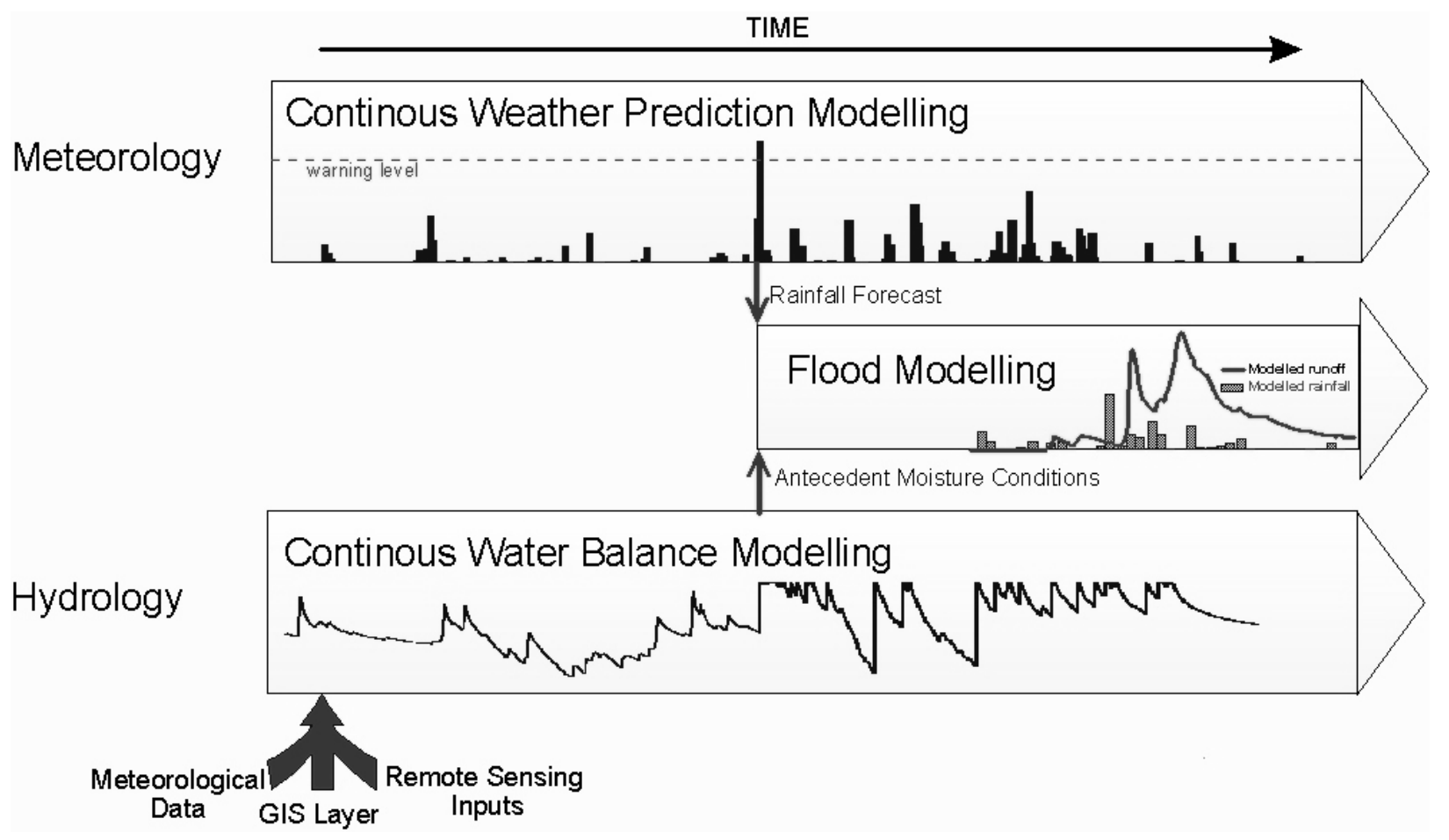

Fig. 1. Concept for coupling meteorological and hydrological models

The remote sensing methods applied in the analyses of the Toce catchment are summarised in Fig. 2, which illustrates which data sets are required and how the processing steps interact. A thorough geometric and atmospheric correction of the satellite data must be performed prior to any successful land surface parameter retrieval. The applied geometric correction consists of an ortho-rectification using a high resolution digital elevation model (DEM) with $50 \mathrm{~m}$ raster size. Adapted from Itten and Meyer (1993), it compensates relief induced pixel displacement of up to $600 \mathrm{~m}$ contained in the unprocessed TM data. Figure 3 (above) shows the resulting orthorectified TM scene of May 30, 1996.

A further processing step consists of the correction of atmospheric and illumination effects in the satellite images. This is mandatory, especially in alpine regions where irradiance conditions vary strongly depending on slope and aspect of each pixel. For this radiometric correction, the atmospheric correction procedure PULREF (Procedure to Use LOWTRAN for REFlectance Calibration) (Bach and Mauser (1994) was improved to account for the illumination effect in mountainous regions.

PULREF models the irradiance on each pixel depending on topographic information (elevation, slope, local solar incidence angle), atmospheric information (visibility, radiosonde profile) and sensor information (time of acquisition, observation geometry, spectral band). Changing atmospheric conditions are considered, depending on elevation and the different illumination of each pixel, as determined by the local solar incidence angle and terrain irradiance. The total signal measured by a sensor is modelled as four components described in Eqn. (1). This allows consideration of the variation of direct and diffuse irradiance, the terrain irradiance and the path radiance for each pixel. The results of this atmospheric correction are surface reflectance values of each spectral band.

$$
L_{\text {total }}=L_{s} \frac{\sin (s z) \sin (s) \cos \left(a z_{\text {rel }}\right)+\cos (s z) \cos (s)}{\cos (s z)}
$$

(direct irradiance component)

$+L_{d} \frac{1+\cos (s)}{2}$

(diffuse irradiance component)

$+\left(L_{d}+L_{s}\right)\left[1-\frac{1+\cos (s)}{2}\right]$

(terrain irradiance component)

$+L_{p}+L_{p 0}$

(path radiance component) 


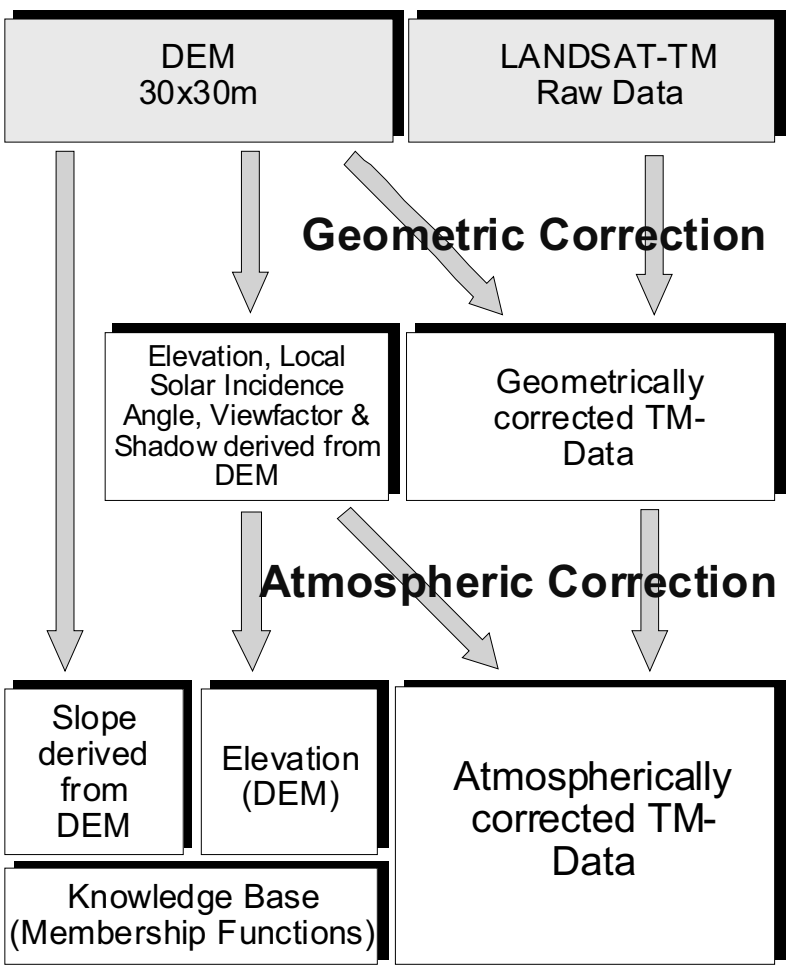

\section{Fuzzy Logic Classification (ENPOC)}

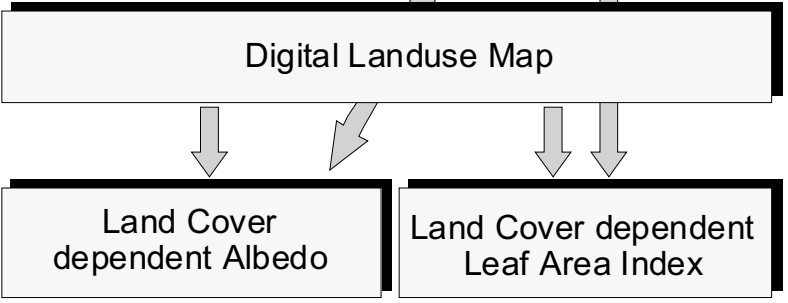

Fig. 2. Applied remote sensing methods for the determination of land use, albedo and LAI

where:

$L_{\text {total }}=$ total irradiance over an inclined surface

$L_{\mathrm{s}}^{\text {total }}=$ direct irradiance over a horizontal surface

$L_{\mathrm{d}} \quad=$ diffuse irradiance over a horizontal surface

$L_{\mathrm{p}}+L_{\mathrm{p} 0}=$ path radiance reaching a sensor

$s z \quad=$ solar zenith angle

$s \quad=$ slope of pixel

$a z_{\text {rel }} \quad=$ relative azimuth between sun and sensor

The horizontal visibility parameterises the optical depth of the atmosphere. It is a function also of aerosol content and varies strongly with elevation. For a proper atmospheric correction in alpine areas, consideration of the influence of the vertical change of the optical depth is crucial. To allow
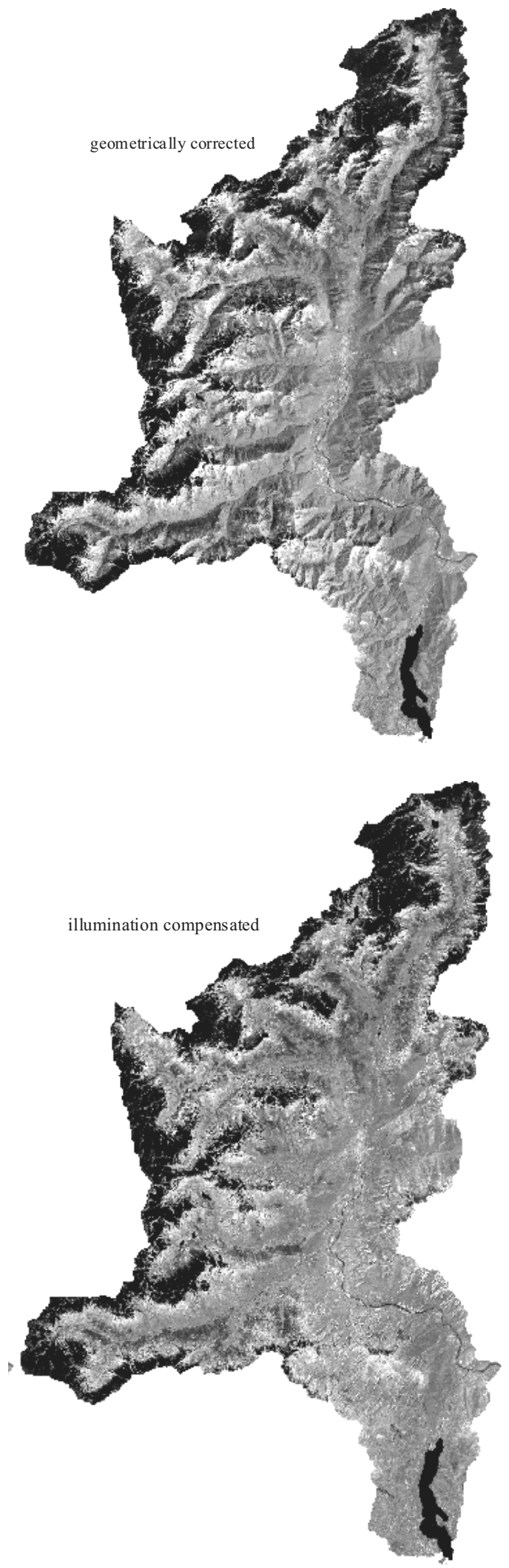

Fig. 3. Band 5 (Short Wave Infrared) of the geometrically corrected (above) and illumination compensated (below) TM scene of May 30, 1996. Note the 3D-effect caused by varying illumination, which is only visible in the geometrically corrected data set. 
for this, a relationship describing the change of horizontal visibility with elevation provided by Elterman (1964) was incorporated in the radiative transfer modelling of the atmosphere. This incorporation results in a spectrally dependent decrease of path radiance and diffuse irradiance $\left(\mathrm{L}_{\mathrm{p}}+\mathrm{L}_{\mathrm{p} 0}, \mathrm{~L}_{\mathrm{d}}\right)$ with elevation while the direct irradiance $\left(\mathrm{L}_{\mathrm{s}}\right)$ increases over high alpine areas.

Using the radiative transfer calculations, the image data are atmospherically corrected and 'normalised' to flat terrain conditions. Figure 3 (below) shows the resulting TM scene of May 30,1996, where illumination effects have been reduced to the widest extent. A spectral band in the short wave infrared was selected for illustration, since, in this wavelength region, diffuse components are weaker. This gives a good impression of the terrain effect and its correction.
Figure 4 illustrates how the spectral signatures of the same land cover under changing illumination conditions relate with and without correction of illumination effects. It is quite obvious that a classification of illumination-compensated images will yield higher precision in considering the difference in spectral signatures without the correction of terrain-induced effects in the imagery.

\section{LAND USE CLASSIFICATION USING A FUZZY LOGIC APPROACH}

Land use information is required both for the hydrological and meteorological models. In alpine areas, the classification of land use from optical multispectral remote sensing data often fails using the standard Maximum Likelihood (ML)
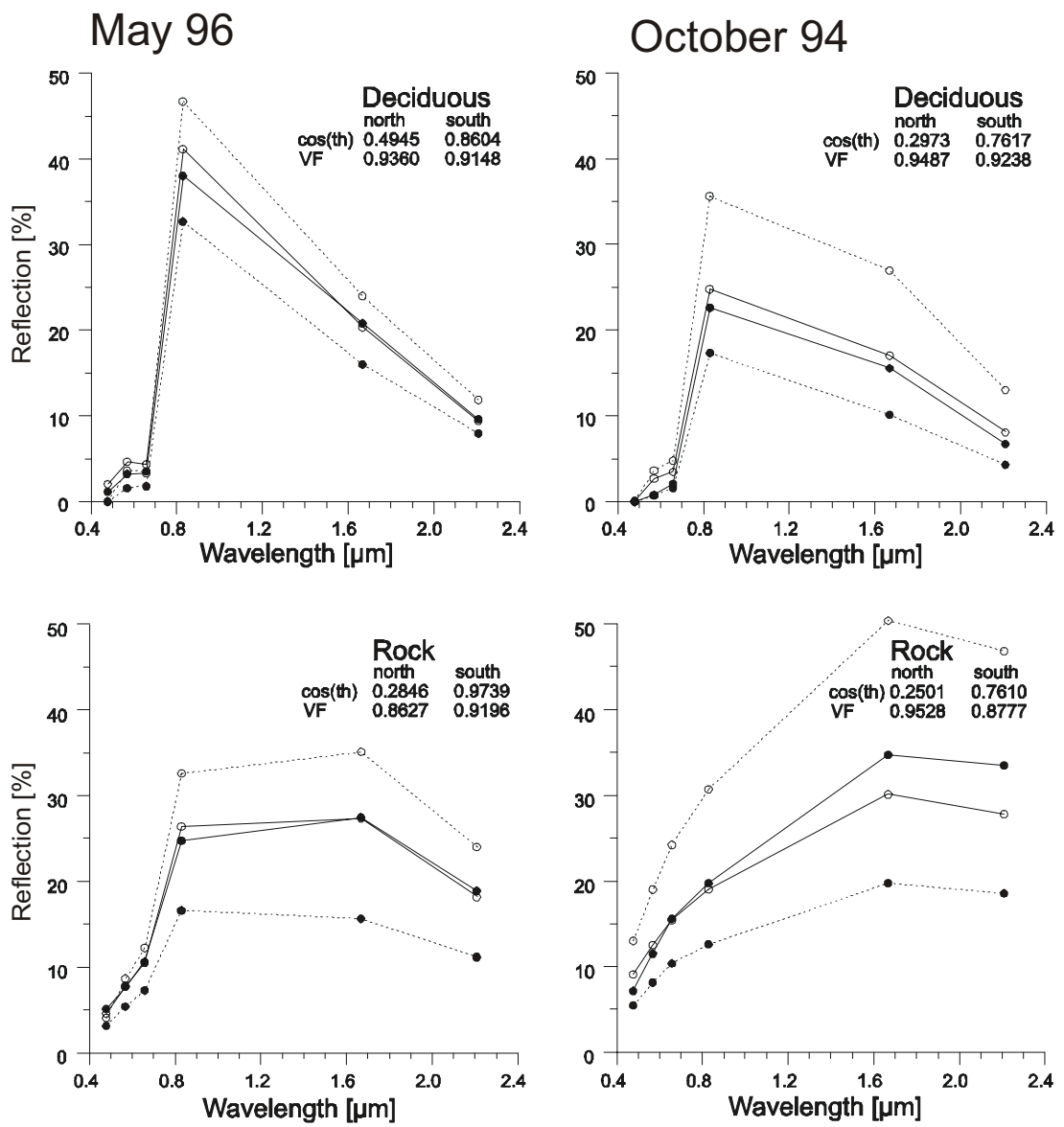

- - - - - southerly aspect, no illumination compensation

-

- - - - northerly aspect, no illumination compensation

$\longrightarrow$ northerly aspect, illumination compensated

Fig. 4. The effect of illumination compensation demonstrated for areas of differing aspect. The spectra of the same land cover show much higher similarity when corrected for terrain induced illumination differences. 
approach. Because of the spatial heterogeneity of surface covers and the high variability of environmental conditions, separability of spectral classes is very difficult, as standard classification methods use only the spectral information of each individual pixel (picture element). They rely on statistical properties to determine to which land use class a pixel has a similar spectral signature. However, in mountainous regions, the strong environmental gradients and different phenological development of vegetation may result in pixels of the same land-use class not necessarily exhibiting equivalent spectral properties. For example, a meadow in the valley is spectrally not comparable with an alpine meadow because their plant development and, hence, their spectral characteristics differ. Also, typical land cover such as rock surfaces and urban areas frequently lead to spectral confusion, resulting in unsatisfactory classification results.

To overcome these difficulties in the land-use classification of a mountainous catchment, a fuzzy logic classification algorithm is applied. The spectral probabilities of the ML classifier are combined with the terrain information on altitude and slope (termed geofactors), that in a fuzzy manner are responsible for the spatial distribution of land cover types.

The possibility of a specific land cover type varies with the geofactors, which influence their spatial distribution. Depending on the geofactor elevation, for instance, the type of forest may change. Thus, at different elevations, each forest type has a changing probability of occurrence; as this change is gradual, the delimitation of the altitude where this forest type occurs is fuzzy. The possibility of a certain land use described by the geofactors can be combined with the ML results based on the spectral information of the satellite imagery, through the application of the Fuzzy Logic decision procedure ENPOC (ENvironmental POssibility $\underline{\text { Classifier, }}$ Stolz (1998)).

The description of these fuzzy limits for a land cover is achieved through membership functions, which describe gradual changes by assigning possibilities for a land cover class to values of a geofactor (Fig. 5). The expression 'possibility' refers here to the grade of membership to a fuzzy set. Physical laws, ecological rules or local observations can be used to define membership functions for each land cover to be classified and for each geofactor available. The whole set of membership functions describing the spatial distribution of classes comprises the knowledge base for the classification.

The applied ENvironmental POssibility Classifier (ENPOC) uses this knowledge base and combines it with the standard ML classifier (Stolz, 1998). In the classification
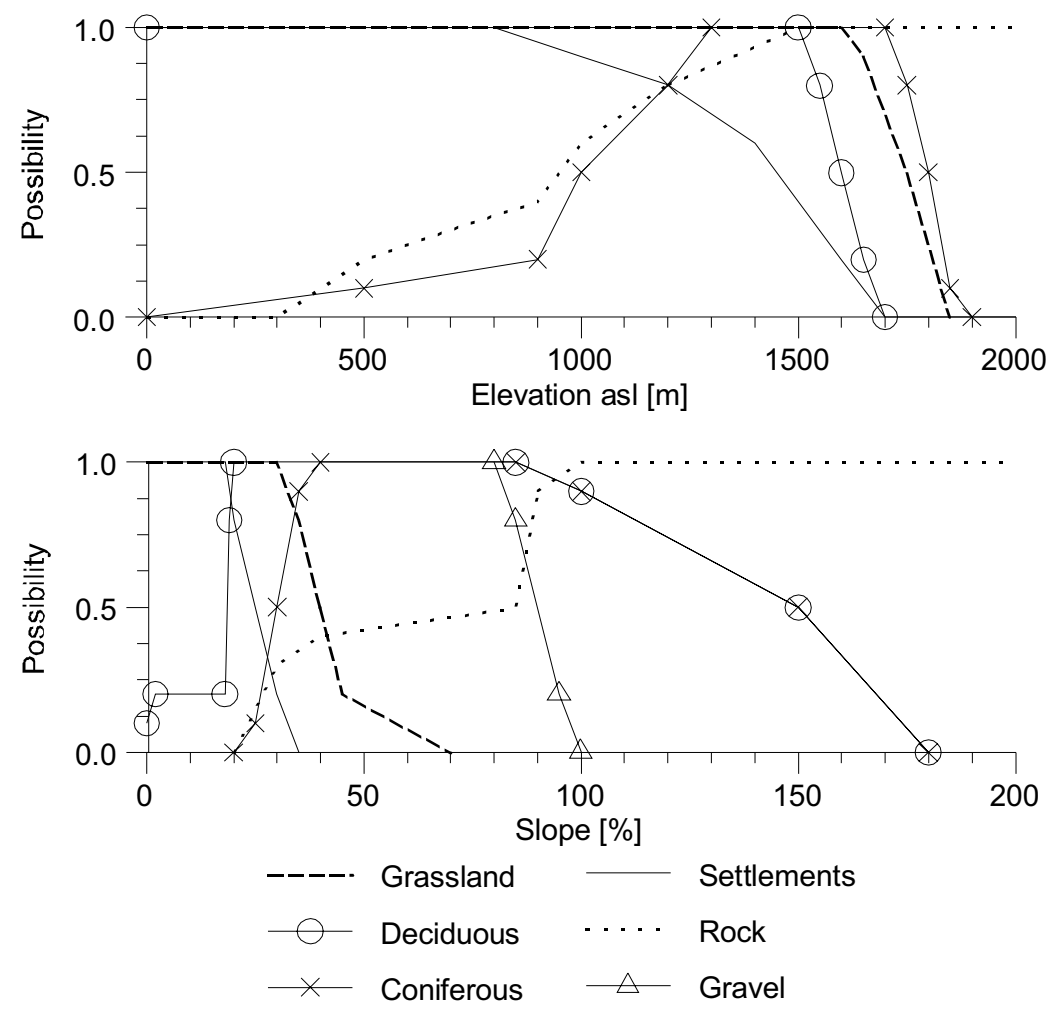

Fig. 5. Selected membership functions from the knowledge base for the fuzzy logic classification (ENPOC) 
of a pixel $x$, the possibilities for each class are determined. The local possibilities $m_{\mathrm{el}}$ and $m_{\mathrm{sl}}$ are taken from the defined membership functions according to the topical values of each geofactor (el=elevation, $\mathrm{sl}=$ slope). The spectral possibilities $m_{\mathrm{sp}}$ are derived by first applying the maximum likelihood classifier to the 6 spectral bands of the TM scene (Eqn. 2). This step yields the probabilities of class membership of a pixel.

$$
p\left(X \mid \omega_{i}\right)=\frac{1}{(2 \pi)^{\frac{n}{2}}\left|C_{i}\right|^{\frac{1}{2}}} \exp \left(-\frac{1}{2}\left(X-m_{i}\right)^{T} C_{i}^{-1}\left(X-m_{i}\right)\right)
$$

where:

$\begin{array}{lll}p\left(X \mid \omega_{i}\right)= & \begin{array}{l}\text { the conditional probability density for } \\ \text { class } \mathrm{w}_{\mathrm{i}}\end{array} \\ \left|C_{i}\right| & =\quad \begin{array}{l}\text { the determinant of the variance-/ } \\ \text { covariance matrix of the training set } \\ \text { for class } \mathrm{w}_{\mathrm{i}}\end{array} \\ C_{i}^{-1} & =\quad \text { inverse variance-/covariance matrix } \\ X^{-1} & \text { data vector of the pixel to be classified } \\ m_{i} & = & \text { mean vector for class } \mathrm{w}_{\mathrm{i}} \\ n & =\end{array}$

To obtain the spectral possibilities for each class, the spectral probabilities are standardised by the maximum probability of the classification of a pixel (Eqn. 3)

$$
\mathrm{m}_{\mathrm{sp}}\left(\mathrm{x} \mid \omega_{\mathrm{i}}\right)=\frac{p\left(X \mid \omega_{\mathrm{i}}\right)}{\max \left[p\left(X \mid \omega_{\mathrm{k}}\right)\right]} ;
$$

Now the spectral possibilities can be combined with the possibilities of each geofactor. The total possibility $\Pi_{\text {total }}$ for each class $\omega_{i}$ at pixel $x$ is calculated using the fuzzy algebraic product (Eqn. 4).

$$
\Pi_{\text {total }}\left(\mathrm{x} \mid \omega_{\mathrm{i}}\right)=\mathrm{m}_{\mathrm{el}}\left(\mathrm{x} \mid \omega_{\mathrm{i}}\right) * \mathrm{~m}_{\mathrm{sl}}\left(\mathrm{x} \mid \omega_{\mathrm{i}}\right) * \mathrm{~m}_{\mathrm{sp}}\left(\mathrm{x} \mid \omega_{\mathrm{i}}\right) ;(4)
$$

Finally, defuzzification is carried out by determining the land cover class with the highest $\Pi_{\text {total }}$ and by assigning this class to the pixel. A pixel remains unclassified when two classes have the same value for $\Pi_{\text {total }}$.

Figure 6 shows the result of the standard ML-classifier compared to the fuzzy logic approach for a TM-scene from May 30th 1996. Clearly, the reduction of noise can be noted. The integration of environmental information helps to produce a realistic image of land cover in an alpine landscape. Accuracy analyses of the classification using an independent set of validation sites showed that the fuzzy logic approach improved the results significantly (see Table 1). Validation sites were selected from homogenous sites elaborated in a field study in September 1997. These were different from the training sets used for the classification. One site per class was available for validation. In Table 1 the term 'producer's accuracy' refers to the number of correctly classified pixels in each class divided by the number of training set pixels used for that class. The user's accuracy is computed by dividing the number of pixels correctly classified in each category by the total number of pixels that were classified into that category. Finally, the overall classification accuracy is obtained by relating the total number of pixels correctly classified to the total number of pixels classified (Lillesand and Kiefer, 2000).

Table 1 compares the accuracies of the classification of single scenes with both approaches (ML and ENPOC). This is improved in all cases through the consideration of geofactors using fuzzy logic rules. For example, the overall classification accuracy of the satellite image from May 1996 increased from $71 \%$ with the ML method to $90 \%$ applying ENPOC.

The two satellite images were classified separately and were combined consecutively using majority decision rules. If a pixel was classified differently on the two occasions, it was assigned the class for which $\Pi_{\text {total }}$ is maximal. Further enhancement of the result was achieved by complementing the multitemporal classifications: if a pixel could not be classified in one image, for instance when pixels were shadowed in the October scene, the classification result of the other image was selected. Likewise, if snow were

\begin{tabular}{|c|c|c|c|c|c|}
\hline & $\begin{array}{l}\text { ML } \\
\text { May }\end{array}$ & $\begin{array}{l}\text { ENPOC } \\
\text { May }\end{array}$ & $\begin{array}{l}M L \\
O c t\end{array}$ & $\begin{array}{l}\text { ENPOC } \\
\text { Oct }\end{array}$ & $\begin{array}{l}\text { Mutiltemp. } \\
\text { ENPOC }\end{array}$ \\
\hline Producer's accuracy [\%] & 60.3 & 83.0 & 56.2 & 82.0 & 92.2 \\
\hline User's accuracy [\%] & 56.8 & 84.5 & 59.4 & 83.1 & 94.0 \\
\hline Overall performance accuracy [\%] & 71.0 & 90.2 & 62.3 & 90.7 & 95.3 \\
\hline
\end{tabular}

Table 1. Accuracy analyses of Maximum Likelihood (ML) and ENPOC fuzzy logic classification of the Toce catchment. Through multitemporal combinations the ENPOC classification achieved best results. 


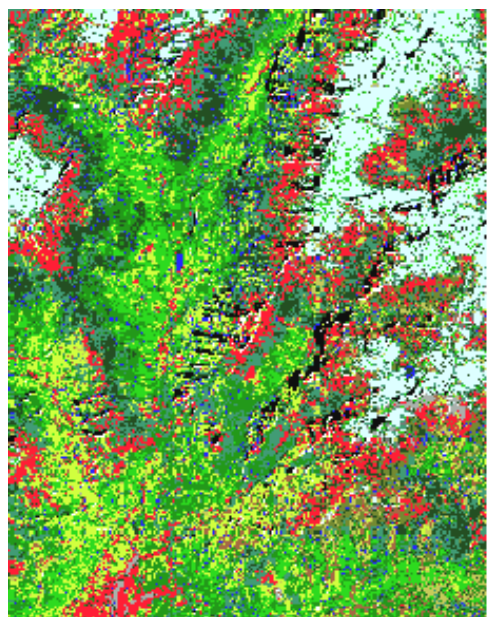

Maximum Likelihood

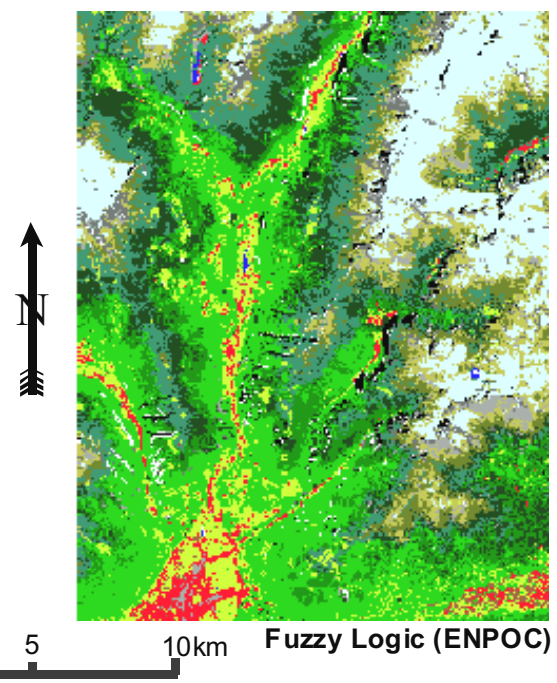

Fig. 6. Comparison of the classifications of land cover using a Maximum Likelihood (left) and Fuzzy Logic approach (right); for legend see Fig. 7

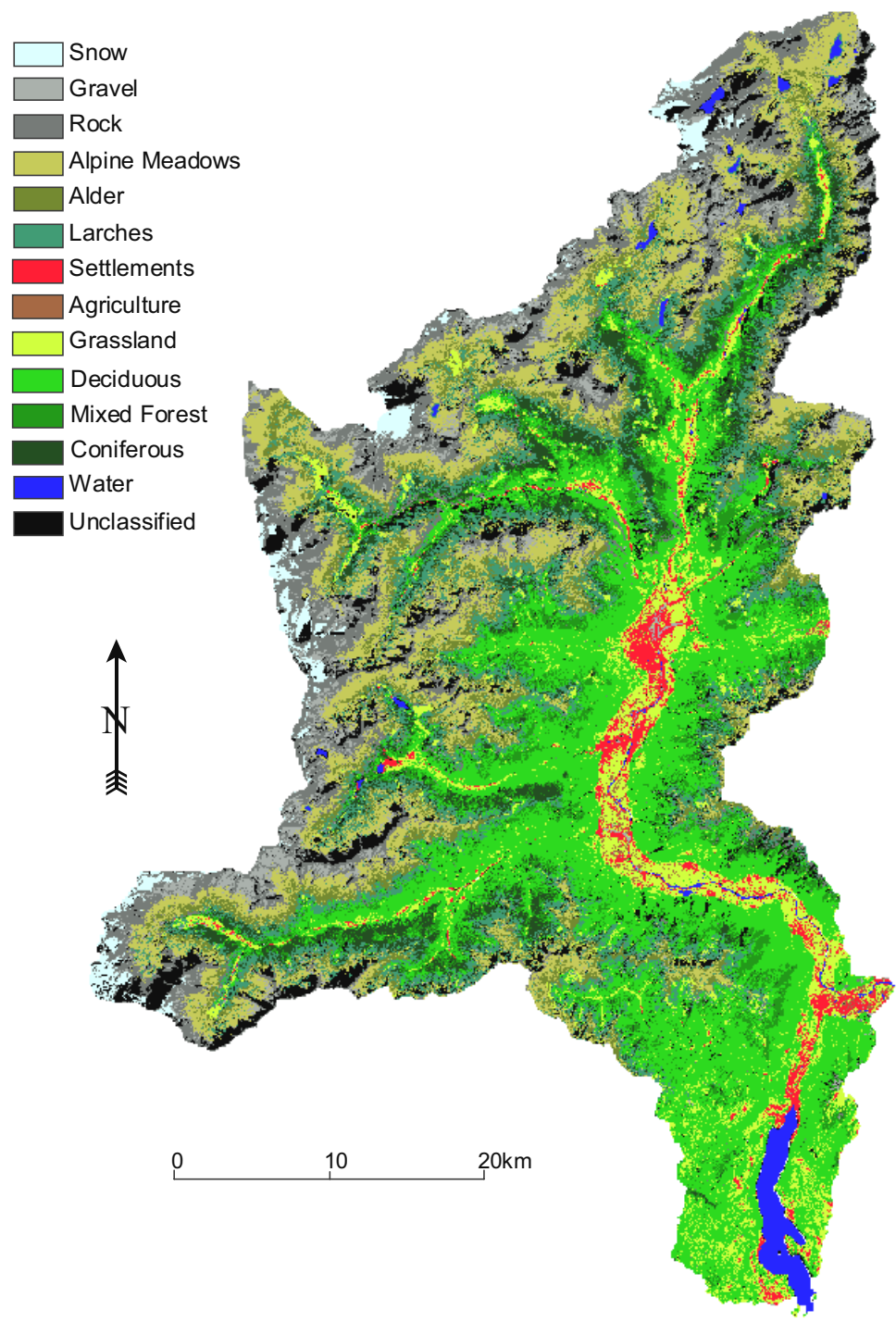

Fig. 7. Land use map derived from a multitemporal LANDSAT-TM data set using a Fuzzy Logic approach 
classified in the image of May, the land use from the October analyses was inserted. The resulting combined land use map, derived from the multitemporal LANDSAT-TM data set, is shown in Fig. 7 for the Toce basin. Using multitemporal TM data of the Toce catchment and consecutive logical combination of the respective classification result increased the overall accuracy to $95 \%$.

\section{DERIVATION OF ALBEDO VALUES}

The albedo of the land surface is important in the energy balance and, thus, for the modelling of hydrological and meteorological processes. The atmospheric correction of the satellite data results in the transformation of radiance measurements of the sensor to spectral reflectance values. Figure 4 shows selected reflectance spectra derived from the TM scenes, with the central wavelengths for each band of the sensor indicated by symbols. The Landsat-TM sensor bands cover only a fraction of the complete reflective spectral range. Therefore, these reflectance values were converted into albedos, which represent the reflectance over the entire range from 0.4 to $2.5 \mu \mathrm{m}$.

The two LANDSAT-TM scenes from May and October were processed to provide albedo-maps of a spring and autumn situation, respectively, using the procedure of Gratton et al. (1993). Weighted functions of the TM-Bands 2, 4 and 7, listed in Table 2, were used to calculate albedo values for different surface covers. The land cover resulting from the Fuzzy Logic classification of the TM-scenes was used to determine the appropriate function applied to a pixel. Table 3 lists the results of the albedo calculation. The temporal dynamics of the albedo of a land surface due to the seasonal development of vegetation canopy is obvious.

\section{DERIVATION OF LEAF AREA INDEX (LAI)}

The leaves of a vegetative canopy can be critical for hydrological modelling. The Leaf Area Index (LAI) describing the leaf area per terrain surface area is highly correlated to Vegetation Indices such as the commonly used
NDVI. The NDVI is derived from near infrared (NIR) and visible bands (VIS) of remotely sensed data:

$$
\text { NDVI }=(\mathrm{NIR}-\mathrm{VIS}) /(\mathrm{NIR}+\mathrm{VIS})
$$

Exponential functions proven to describe the relationship between LAI and NDVI were used to derive LAI values for the Toce catchment using an exponential equation proposed by Spanner et al. (1990) for coniferous forests in the Rocky Mountains. Equation (6) was adjusted to formulate the LAI/NDVI relationship for different vegetation types.

$\mathrm{LAI}=\mathrm{a}^{*} \mathrm{NDVI}^{\mathrm{b}}$

For grassland, alpine meadows and agriculture, the function could be fitted to a relationship of Ludwig et al. (1999) and for deciduous and coniferous forests that of Gregoire and Raffy (1997) These functions were then used to determine LAI values. All LAI/NDVI relationships rely on field measurements and the fitted functions represent these findings through the coefficients $a$ and $b$ in Eqn. (6). Again, the Fuzzy Logic classification results served to select the appropriate function to be applied for an individual pixel. The results of the LAI calculation for individual land use classes are given in Table 4; the total means weighted for the areas were 2.9 and 2.0 for May and October respectively.

Figure 8 shows the albedo and LAI map derived from the LANDSAT-TM scene of May, 30th 1996. The albedo values of up to $60 \%$ refer to snow which still covers the higher altitudes in the spring scene. The lowest albedo values of approximately $2 \%$ belong to water bodies like Lago Maggiore.

The spatial distribution of the leaf area behaves quite differently from the albedo. Minimum LAI values of zero refer to areas free of vegetation at higher altitudes. Maximum values occur on the forest stands on the slopes of the valleys. Compared to the leaf area of forest, the agriculture and grassland in the Toce valley have LAI values between 1 and 2.

Table 2. Land cover dependent weighted functions for the retrieval of albedo (a) from LANDSAT-TM-band-calculated reflectances (TM2 - TM7) (after: Gratton et al., 1993)

\begin{tabular}{ll} 
Land cover type & Functions for albedo retrieval from TM bands \\
\hline Bare ground, water bodies & $\mathrm{a}=0.493(\mathrm{TM} 2)+0.507(\mathrm{TM} 4)$ \\
Vegetated surfaces & $\mathrm{a}=0.493(\mathrm{TM} 2)+0.353(\mathrm{TM} 4)+0.154(\mathrm{TM} 7)$ \\
Snow & $\mathrm{a}=0.493(1.12[\mathrm{TM} 4])+0.203(\mathrm{TM} 4)+0.150(0.30[\mathrm{TM} 4])+0.154(\mathrm{TM} 7)$
\end{tabular}


Table 3. Albedo values of individual surface-covers on a spring and autumn day in the Toce basin.

\begin{tabular}{|c|c|c|c|c|c|c|}
\hline \multirow[b]{2}{*}{ Land use class } & \multicolumn{3}{|c|}{ May 30th, 1996} & \multicolumn{3}{|c|}{ October 16th, 1994} \\
\hline & Mean & Dev. & $\%$ of Area & Mean Albedo & St. Dev. & $\%$ of Area \\
\hline Snow & 47.4 & 10.2 & 23.3 & 40.2 & 16.3 & 1.5 \\
\hline Settlements & 16.5 & 2.3 & 2.2 & 10.5 & 3.2 & 1.8 \\
\hline Water & 2.3 & 2.3 & 1.1 & 2.3 & 1.5 & 1.3 \\
\hline Grassland & 17.8 & 2.8 & 7.1 & 15.0 & 2.4 & 3.0 \\
\hline Agriculture & 19.8 & 1.4 & 0.3 & 12.9 & 1.5 & 0.2 \\
\hline Coniferous Forest & 11.6 & 2.7 & 5.5 & 3.9 & 2.2 & 7.4 \\
\hline Rock & 20.0 & 3.5 & 2.7 & 11.4 & 5.6 & 9.8 \\
\hline Gravel & 21.4 & 3.3 & 2.1 & 20.0 & 3.6 & 3.5 \\
\hline Larches & 13.2 & 1.9 & 10.2 & 8.3 & 3.7 & 10.2 \\
\hline Deciduous Forest & 17.2 & 2.1 & 25.4 & 10.8 & 2.0 & 21.5 \\
\hline Mixed Forest & 14.5 & 1.7 & 6.6 & 10.4 & 2.8 & 4.6 \\
\hline Alpine Meadows & 20.8 & 4.1 & 7.4 & 14.9 & 2.8 & 11.0 \\
\hline Alder & 15.8 & 1.3 & 4.3 & 12.0 & 1.3 & 4.0 \\
\hline Unclassified/Shadow & - & - & 1.8 & - & - & 20.2 \\
\hline
\end{tabular}

\section{Application of remotely sensed variables in water balance models}

\section{THE WATER BALANCE MODEL PROMET}

PROMET (PRocess Oriented Multiscale EvapoTranspiration model) is a family of land-surface processesmodels that describe the actual evapotranspiration at different scales, ranging from field based modelling to microscale and mesoscale modelling (Mauser 1989, 1991; Mauser and Strasser, 1997). PROMET comprises a kernel model, which handles the modelling of the actual evapotranspiration process, and a spatial data modeller, which consists of a set of parameter models providing and organising adequate spatial input data on the field-, microand mesoscale. The schematic structure of PROMET is shown in Fig. 9.
Process modelling in PROMET

PROMET is based on the following assumptions and formalisms:

- The kernel model uses the Penman-Monteith equation (Eqn. 7) as an approximation to the actual evapotranspiration for a large variety of natural conditions.

$$
\lambda E=\frac{1}{\Delta+\gamma\left(r_{a}+r_{c}\right) / r_{a}}\left[\left(R_{n} G\right) \Delta+\frac{\rho_{c_{p}}}{r_{a}}\left(e_{s}(T(z)) e(z)\right)\right]
$$

with $\lambda=$ latent heat of vaporisation of water

$E=$ water vapour flux per unit area

$\Delta=$ slope of saturated water vapour curve

$\gamma=$ psychrometer constant

$r_{a}=$ aerodynamic resistance

$r_{c}=$ canopy resistance

Table 4. Land use dependent functions for the retrieval of LAI from NDVI and resulting mean LAI values of vegetated surface covers on a spring and autumn day in the Toce basin as derived from satellite measurements.

\begin{tabular}{llccccc}
\hline \multirow{2}{*}{$\begin{array}{l}\text { Land use class } \\
\text { LAI } a * \text { NDVI } b\end{array}$} & \multicolumn{3}{c}{ May 30th, 1996} & \multicolumn{2}{c}{ October 16th, 1994 } \\
& $a$ & $b$ & Mean LAI & St. Dev. & Mean LAI & St. Dev. \\
\hline Grassland & 1.60 & 3.00 & 1.7 & 0.8 & 1.3 & 0.8 \\
Agriculture & 1.60 & 3.00 & 0.8 & 0.5 & 0.1 & 0.1 \\
Coniferous & 1.86 & 6.06 & 6.0 & 5.3 & 4.7 & 4.9 \\
Larches & 1.86 & 6.06 & 1.8 & 2.4 & 1.8 & 2.4 \\
Deciduous & 1.63 & 4.70 & 3.9 & 2.0 & 2.2 & 1.4 \\
Mixed Forest & 1.75 & 5.40 & 4.6 & 3.8 & 2.7 & 2.4 \\
Alpine Meadows & 1.60 & 3.00 & 0.2 & 0.3 & 0.3 & 0.2 \\
Alder & 1.63 & 4.70 & 0.2 & 0.2 & 0.5 & 0.4 \\
\hline
\end{tabular}



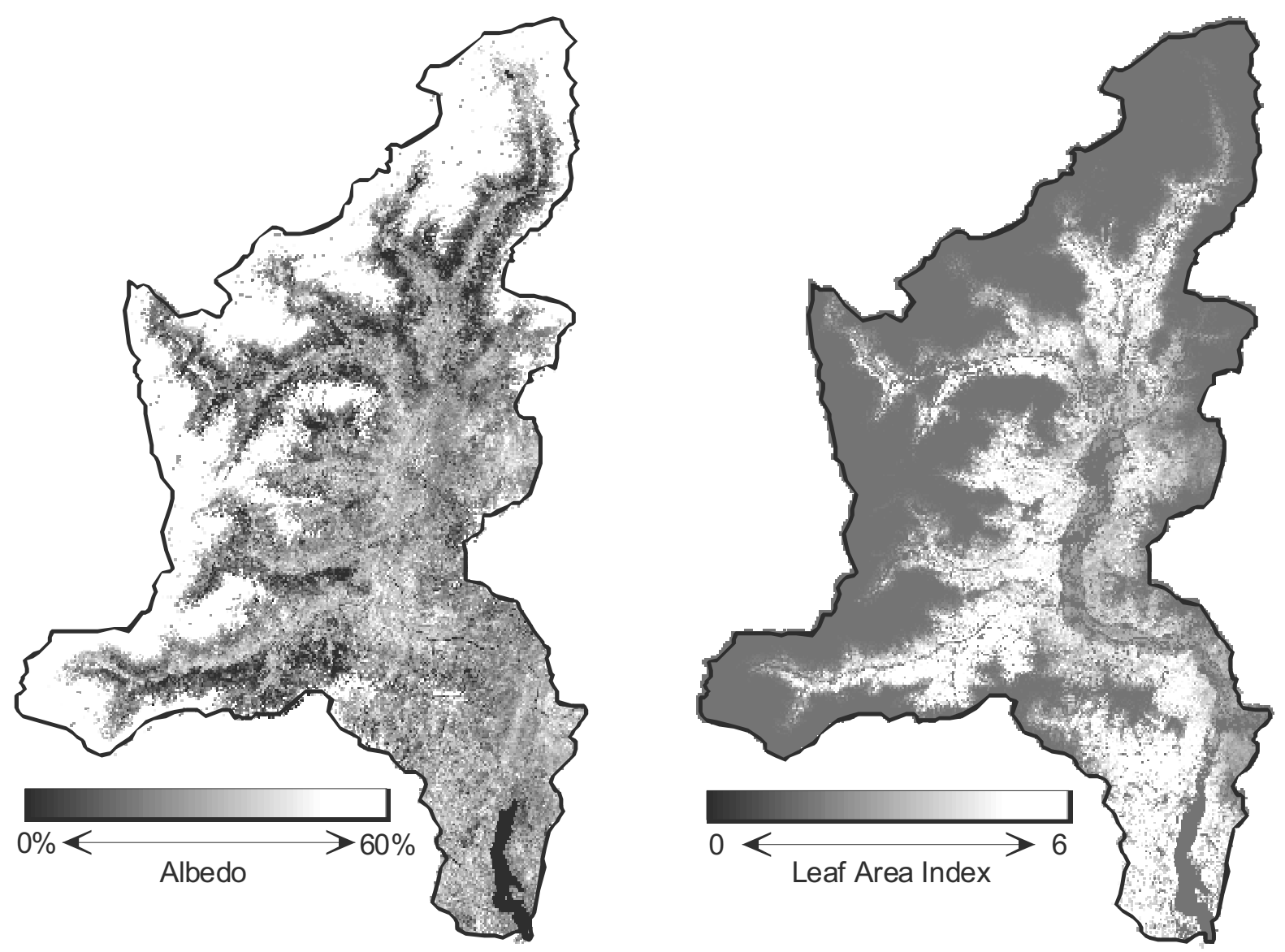

Fig. 8. Spatial distribution of Surface Albedo and LAI in the Toce Basin on May 30 th 1996

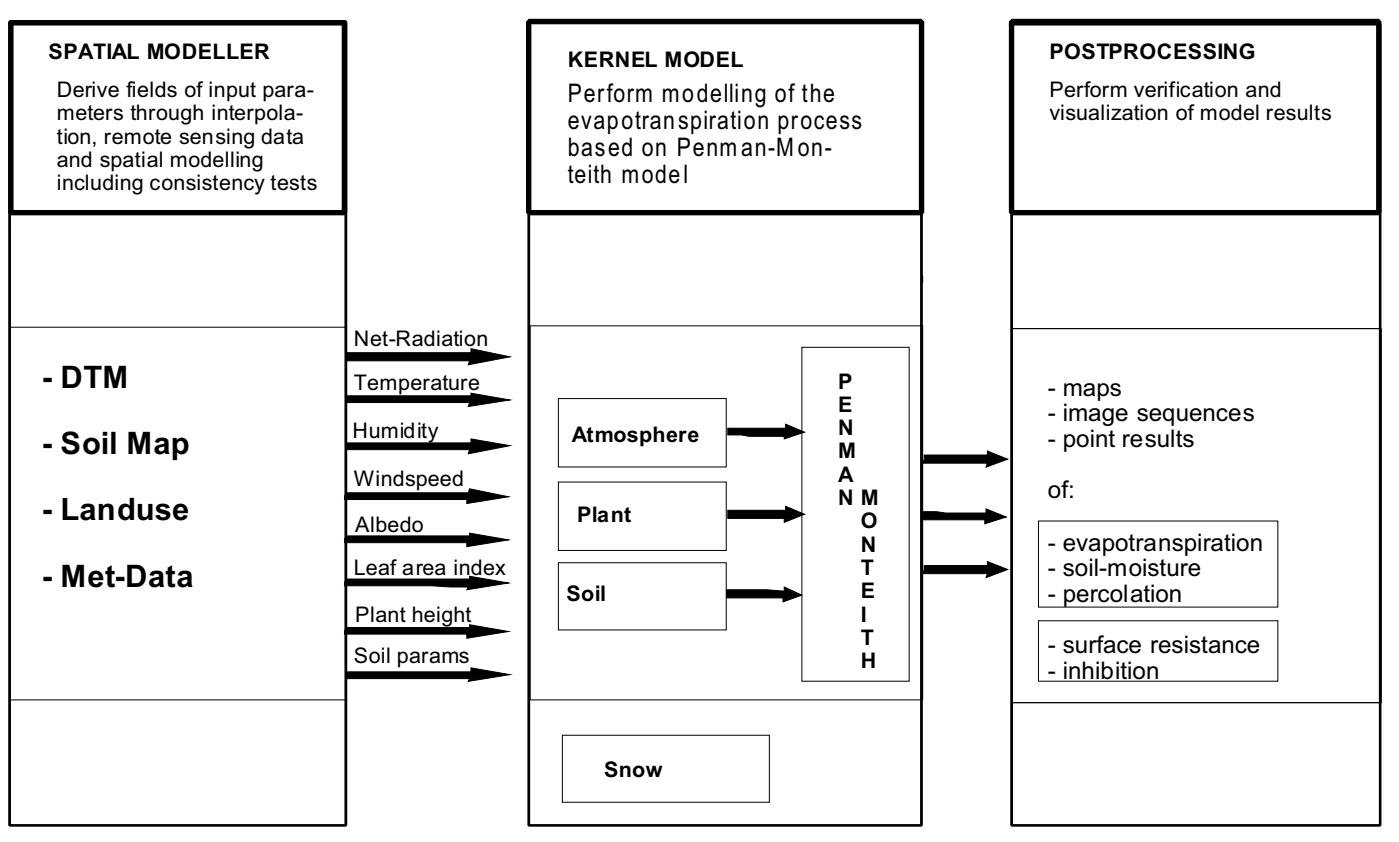

Fig. 9. Schematic structure of PROMET 


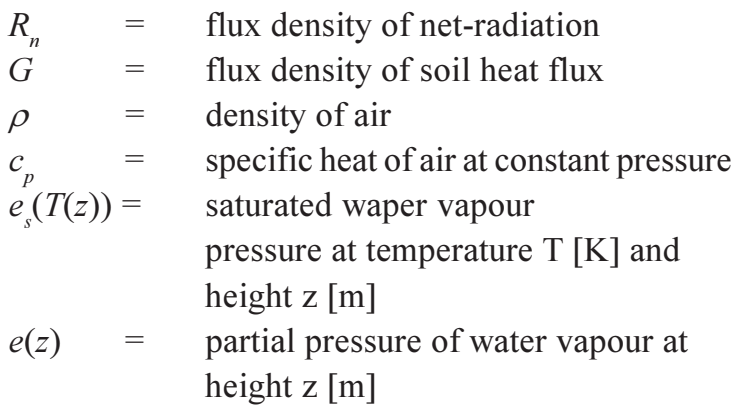

- In the Penman-Monteith equation, the influence of the land-surface and its reaction to environmental conditions is summarised in a surface resistance/ conductance. Stomatal resistance in the model is determined as a function of intercepted $P A R$. Temperature, humidity and soil moisture are introduced as limiting factors for the stomatal resistance in the form of an environmental influence function $g$ :

$$
r_{s}(P A R)=\frac{r_{s \min }+\frac{b(P A R)}{P A R} \cdot r_{s \min }}{g}
$$

with:

$$
\begin{aligned}
& r_{s}=\text { stomatal resistance }\left(\mathrm{m}^{-1}\right) \\
& r_{s \text { min }}=\text { plant specific minimum stomatal resistance }\left(\mathrm{m}^{-1}\right) \\
& P A R=\text { photosynthetically active radiation }\left(\mathrm{Wm}^{-5}\right) \\
& b \quad=\text { plant specific parameter } \\
& g \quad=\text { environmental influence function }
\end{aligned}
$$

- Plant growth in the model is represented through the temporal evolution of green leaf area index (LAI), plant height and albedo. These can be provided through analyses of remote sensing data. LAI is used in a 10layer radiative transfer model (Norman, 1979) to convert the incoming PAR into fractions of shaded and sunlit leaves depending on the solar elevation angle and assuming that the leaf orientation is spherical. The fraction of shaded and sunlit leaf area is used to convert the stomatal conductance into a canopy conductance.

- Soil water balance, soil suction and moisture in the rootzone are determined through a simplified solution of the Richards equation (Eagleson, 1978). For homogeneous soils, the change in soil moisture $\Theta$ is calculated using the one-dimensional Philip equation, with time $t$, soil depth $z$, hydraulic conductivity $K$ and diffusivity $D$ :

$$
\frac{\partial \Theta}{\partial t}=\frac{\partial}{\partial z}\left[D(\Theta) \frac{\partial \Theta}{\partial z}\right]-\frac{\partial K(\Theta)}{\partial z}
$$

The static soil hydraulic parameters necessary for the calculations are pore volume, pore size distribution index (Brooks, 1966) and bubbling pressure head. The actual soil suction is determined from the soil moisture budget, which results from infiltration, evapotranspiration, percolation, surface runoff and capillary rise. Only one soil layer was considered in the soil model with a depth variable depending on the rooting depth of the land cover, which can vary from 20 to $200 \mathrm{~cm}$.

- The snow cover is modelled in a one-layer sub-model called ESCIMO (Energy Balance Snow Cover Integrated MOdel) (Strasser and Mauser, 2001). ESCIMO is designed as a physically-based model for the hourly simulation of the energy balance, the water equivalent and the melt rate of a snow cover. To simulate the energy balance, the short- and long-wave radiation, the sensible and latent heat fluxes, the energy conducted by solid or liquid precipitation and a constant soil heat flux are taken into account.

A detailed description of PROMET is in Mauser and Schädlich (1998) which also describes the results of sensitivity studies and validation with station measurements. A long term application with 30 years of model calculations with PROMET in the Weser catchment is demonstrated and validated in Strasser and Mauser (2001).

Lateral flows of water and energy are considered only in an extended version of PROMET (Ludwig, 2000), which was not available for this study. Therefore, the applied PROMET version treated each model cell independently. Runoff concentration and flood routing were not calculated.

\section{Spatial modelling in PROMET}

The kernel model of PROMET is embedded in a GIS shell, which provides and handles the necessary spatially distributed input parameters. The following spatial parameter fields are used as input to PROMET:

- $\quad$ soil physical parameters derived from soil maps

- terrain parameters derived from a digital terrain model,

- land use information from classification of remote sensing data,

- meteorological variables: solar irradiance, airtemperature, wind-speed, relative humidity and precipitation, which are interpolated between station measurements using terrain parameters.

As meteorological inputs, PROMET needs the spatial distribution of the five meteorological variables for the whole catchment. In interpolation, the elevation of each pixel is required to determine the terrain dependency of the respective meteorological variable. Except for irradiance, this is achieved through correlation between measured 
meteorological variable (e.g. temperature or rainfall) and the elevation of the station. A spatial bilinear interpolation is then performed on the residues of the regression. Finally, the trend surface, which is determined by the regression and calculated from the DEM, is added to the spatially interpolated field. This method ensures that the station measurement itself is not modified but that the topography in the regions between stations is considered.

The spatial distribution of net radiation is modelled according to the geographic position of the modelled pixel; its slope and aspect, together with the solar elevation determine the local illumination conditions. Especially in alpine regions, the terrain dependent simulation of net radiation is crucial.

\section{MODEL SETUP FOR THE TOCE CATCHMENT}

The following spatial parameter fields are used for the simulations in the Toce catchment:

- Soil physical parameters were derived from a water permeability map provided by the University of Brescia (Bacchi and Ranzi, 2000). The permeability map is based on an intense field survey of 60 samples widespread in the Toce catchment. These measurements were assumed to be representative for a soil type and a map with 50m spatial resolution was provided.

- The Italian Regione Piemonte DEM was made available at a $50 \mathrm{~m}$ spatial resolution by DIIAR, Politecnico di Milano.

- Land use, LAI and albedo were derived from remote sensing data as described earlier.

- Meteorological fields of solar irradiance, airtemperature, wind-speed, relative humidity and precipitation were interpolated from station measurements. Since not all these parameters were available at all stations, the missing measurements were modelled on the basis of the available data. Eighteen stations were finally used for the interpolation of the meteorological input fields.

The water balance simulations used a grid size of $100 \mathrm{~m}$.

\section{Model results}

Model runs were conducted for the whole Toce catchment as well as for selected points in the catchment which differed in their physiographic attributes (e. g. altitude, soil type or land use). The annual courses of meteorological variables selected on the basis of the point calculations obviously demonstrate the influence of the physiographic attributes on the meteorological variables. As shown in Fig. 10, a high snow water equivalent (upper left grey curve) until the beginning of May caused by a rather high altitude is the reason for a decrease in soil moisture under the snow that suddenly increases when the snow melts. The earlier starting evapotranspiration of agriculture in the valleys leads to a stronger decrease of soil moisture in summer compared to the forested regions. The difference in soil moisture can further be explained by the different soil types. So even a high precipitation (e.g. middle of August) is not sufficient to saturate the loamy sand, whereas the clay soil reaches saturation.

Spatial model runs for the whole Toce basin were carried out from 1994 to 1997. For calculating the spatially distributed water balance, the model results for 1996 and 1997 were used. The modelled annual sums of precipitation and evapotranspiration were averaged for these two years. The runoff was calculated as the difference between precipitation and evapotranspiration. Figure 11 shows the results. The mean modelled water balance for the whole basins is $1486 \mathrm{~mm}$ precipitation, $366 \mathrm{~mm}$ evapotranspiration and thus $1120 \mathrm{~mm}$ runoff. The comparison of this runoff value with measurements at Candoglia gauge station (1018 $\mathrm{mm}$ ) shows a good agreement, especially considering that the measurements (both station rainfall and runoff) are not free of errors and the applied water balance approach does not consider changes in the water storage in the soil and snow pack.

The low values of precipitation in the South West corner of the catchment with high elevations may be surprising in Fig. 11. However the nearby Passo del Moro rainfall gauge measured only an annual precipitation of $507 \mathrm{~mm}$ during the years 1996 and 1997. Since the station measurements are crucial for the spatial interpolation of the meteo-fields, this region is dominated by the station measurement.

The water balance calculations were performed on an hourly time interval. Thus, for any time during the model calculation it is possible to determine the soil moisture distribution. This information is especially important before heavy rainfall, because the soil moisture determines whether rainfall produces runoff or is stored in the soil layer. Therefore for all Toce flood events addressed in the course of the RAPHAEL project the soil moisture distributions prior to the floods were calculated, stored and provided as starting conditions for the hydrological flood models.

The results are shown in Fig. 12. In the interpretation of the soil moisture map, one has to consider that the soil moisture refers to the root zone that varies strongly depending on the land use (e.g. $10 \mathrm{~cm}$ for alpine meadows, $100 \mathrm{~cm}$ for agriculture, $150 \mathrm{~cm}$ for deciduous forest). The relatively low soil moisture values reflect the higher 

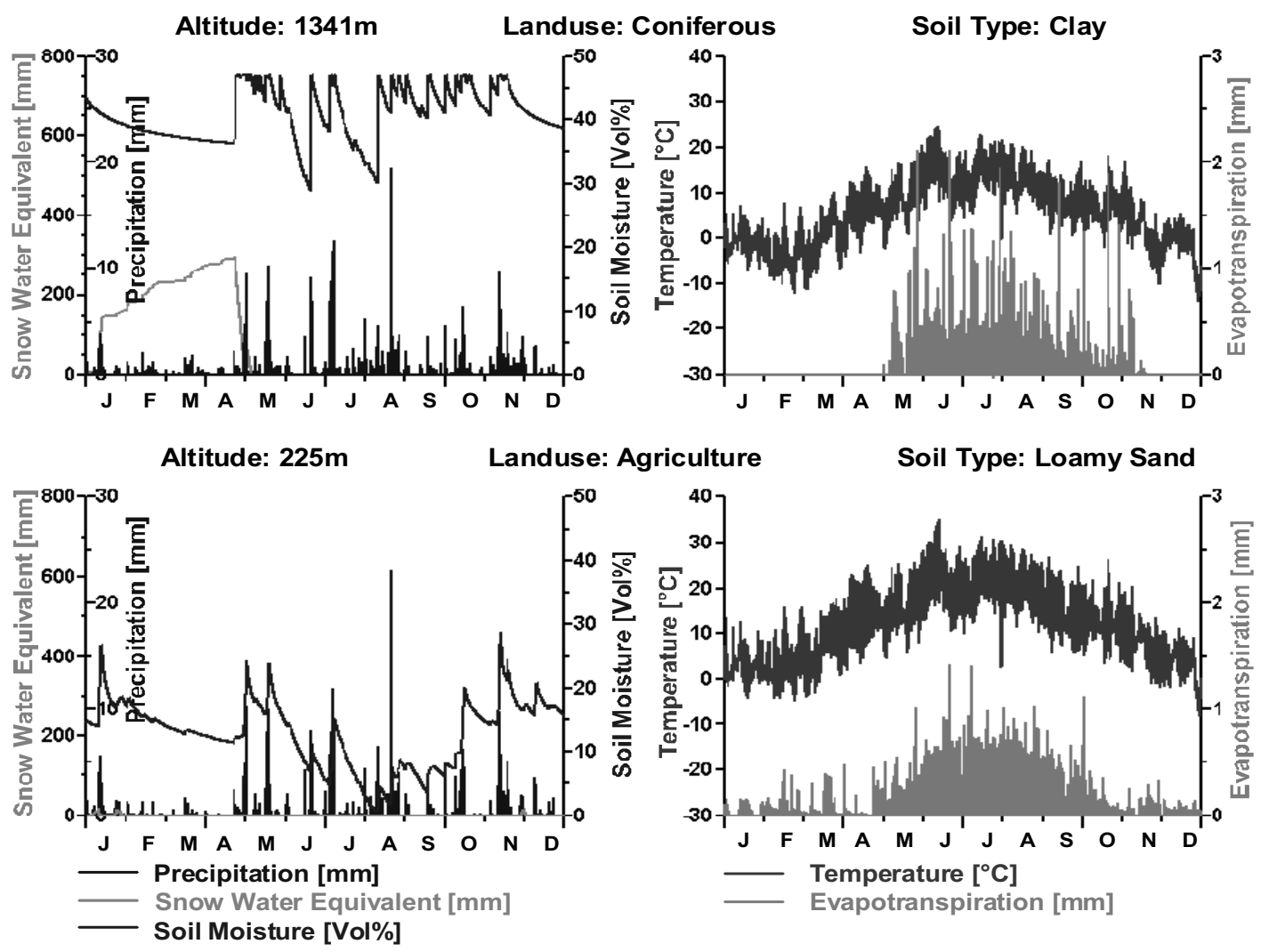

Fig. 10. Annual courses of PROMET model results for two selected land-use types in 1996

transpiration of the agriculture in the valley and the unconsidered lateral flow in the performed PROMET simulations.

In Fig. 12 it becomes obvious that the spatial and temporal variation of this hydrologically critical parameter is very high. Using the PROMET water balance model and satellite information it is possible, however, to derive this information to characterise the status of a catchment prior to a flood event.

\section{Discussion}

Land cover maps are crucial to hydro-meteorological modelling. With the proposed fuzzy logic approach, costefficient derivation of land cover information from satellite imagery can be obtained, even in rugged mountainous terrain. Other land cover dependent variables such as the albedo of the Earth's surface as well as the Leaf Area Index (LAI) can be derived, respectively, from spectral reflectance values by land cover dependent spectral integration and by formulating land cover dependent NDVI-LAI relationships from classification results and remote sensing data. Based on the ENPOC classification, both variables were derived within the RAPHAEL-project for an improved extraction of surface parameters in alpine areas.

Concerning the image processing, further improvements to the radiometric correction can be expected by taking into account the irradiance of surrounding surfaces as well as anisotropy of diffuse irradiance, as described in Sandmeier (1995). These were, however, not implemented in this study since they were expected to be only of secondary importance. The spatial resolution of the DEM has a larger influence. Unfortunately, the original spatial resolution of the DEM did not comply fully with the requirements for optimal results of a radiometric correction, which would need a resolution of $50 \%$ of the pixel size, i.e. $15 \mathrm{~m}$. The lower resolution of the DEM compared to the satellite image creates artefacts in the corrected images. These become most obvious along the mountain crests. Improvements in image processing should thus start with an improved DEM.

It was demonstrated that a water balance model like PROMET can be driven with remotely-sensed land surface parameters. The water balance of the Toce catchment was calculated with PROMET without any calibration of the model. The comparison of measured and modelled runoff showed the quality of the model. This agreement could be 


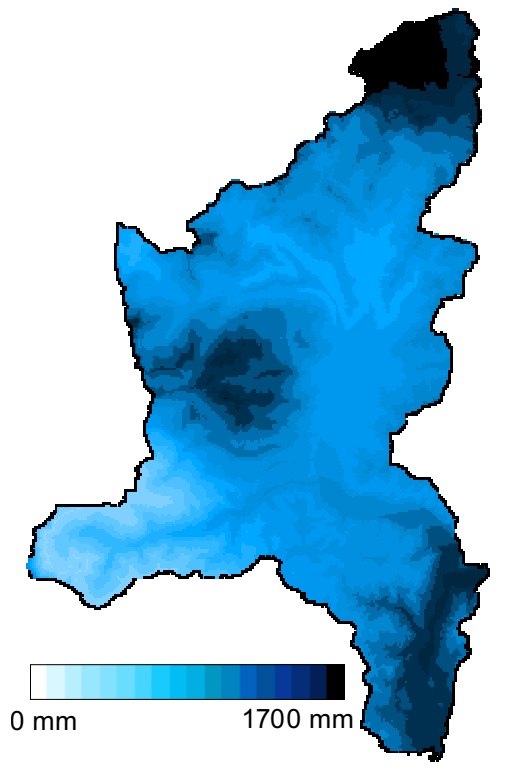

Modelled Precipitation

Mean Value: $1486 \mathrm{~mm}$

Min: $690 \mathrm{~mm}$

Max: $2320 \mathrm{~mm}$

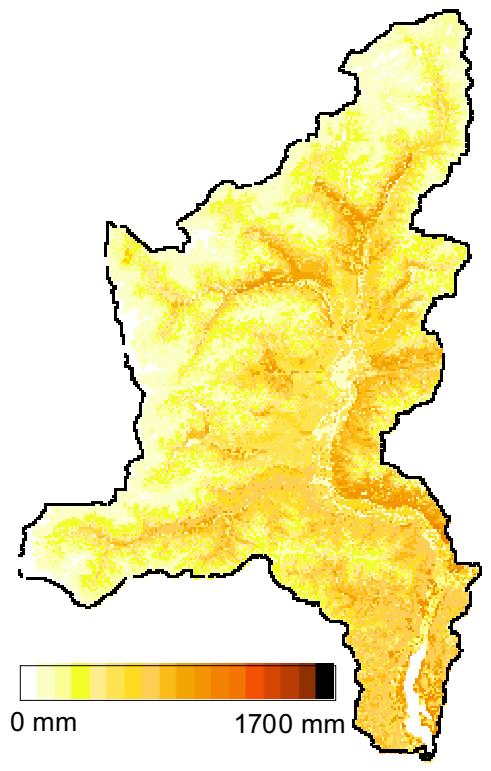

Modelled Evapotranspiration

$$
\begin{gathered}
\text { Mean Value: } 366 \mathrm{~mm} \\
\text { Min: } 0 \mathrm{~mm} \\
\text { Max: } 1110 \mathrm{~mm}
\end{gathered}
$$

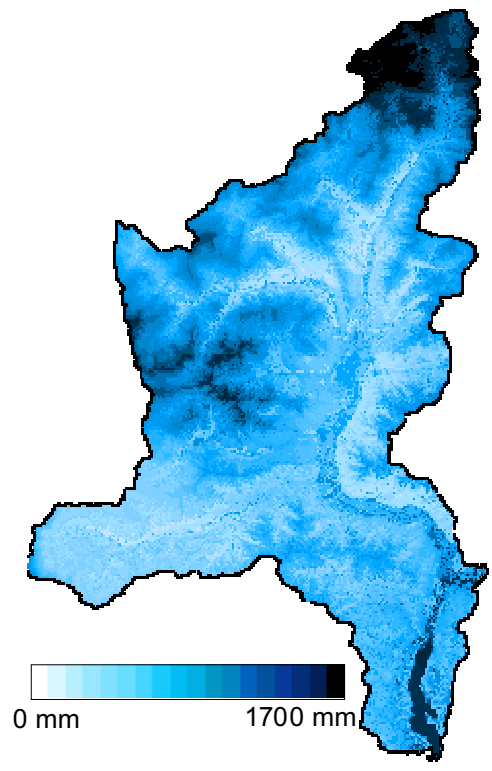

Calculated Runoff

Mean Value: $1120 \mathrm{~mm}$

Min: $260 \mathrm{~mm}$

Max: $2320 \mathrm{~mm}$

Fig. 11. Water balance for the Toce basin based on PROMET model results from 1996 and 1997
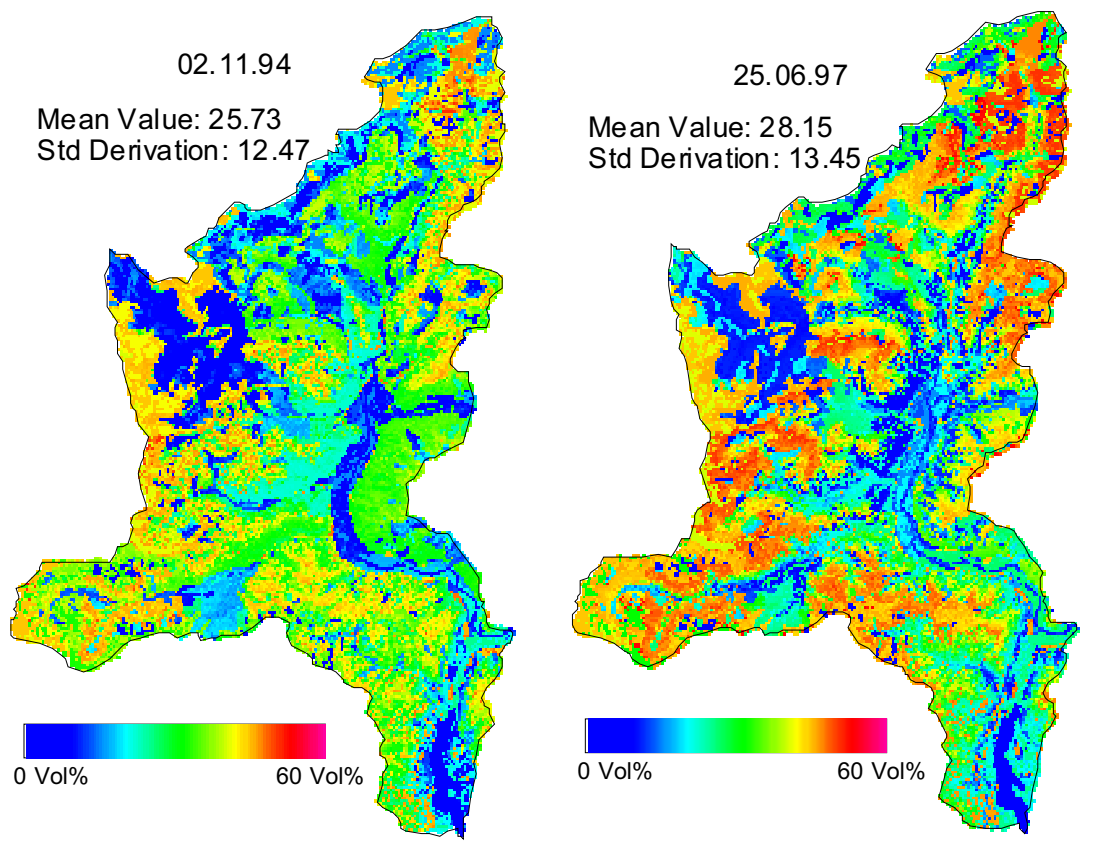

Fig. 12. Spatial distributed soil moisture in the Toce basin prior to the selected flood events

achieved without calibration because the land surface was well represented by using the remotely-sensed input variables. Unfortunately, runoff concentration and flood routing were not calculated. Thus hydrographs could not be provided to compare the model results with measured discharges. Also, comparison of the simulated soil moisture with measured values was not possible, since the MAP Intensive Observing Periods with extensive field survey in 
the Toce area (Ranzi et al., 2003) occurred only after the end of the RAPHAEL project.

Nevertheless, the concept that remotely-sensed information can be used for hydrological parameterisation in Alpine catchments has been justified. Further, since remote sensing observations are available all over the globe, the methodology can also be applied to a wide range of catchments outside the Alps.

\section{Acknowledgements}

This work was funded within the EU-Project RAPHAEL (ENV4-CT97-0052) co-ordinated by DICBS, University of Brescia, Italy. Many thanks to the RAPHAEL team, who facilitated the success of the study, specially to Robert Ranzi (DICBS) who supported this work significantly. Thanks also to the reviewers for their profound and helpful comments.

\section{References}

Bacchi, B. and Ranzi R., 2000. Raphael Runoff and Atmospheric Processes for flood HAzard forEcasting and control project. Final report of EU contract ENV4-CT97-0552

Bacchi, B. and Ranzi R., 2003. The Raphael project: an overview. Hydrol. Earth Syst. Sci., 7, 784-798.

Bach, H. and Mauser, W., 1994. Atmospheric correction of hyperspectral data in terms of the determination of plant parameters. In: Recent Advances in Remote Sensing and Hyperspectral Remote Sensing, EUROPTO Series, SPIE 2318. $52-62$.

Baldocchi, D.D., Hicks, B.B. and Camara, P., 1987. A canopy stomatal resistance model for gaseous deposition to vegetated surfaces. Atmos. Environ., 21, 91-98.

Brooks, R.H. and Corey, A.T., 1966. Properties of porous media affecting fluid flow. J. Irrig. Drain. Eng. Div., ASCE., IR2, 61-88.

Eagleson, P.S., 1978. Climate, Soil and Vegetation: A simplified model of soil water movement in the liquid phase. Water Resour. Res., 14, 722-730.

Elterman, L., 1964. Rayleigh and Extinction Coefficients to $50 \mathrm{~km}$ for the Region $0.27 \mu$ to $0.55 \mu$. Applied Optics, 3, 1139-1147.

Gratton, D.J., Howarth, P.J. and Marceau, D., 1993. Using Landsat5 thematic mapper and digital elevation data to determine the net radiation field of a mountain glacier. Remote Sens. Environ., 43, 315-331.

Gregoire, C. and Raffy, M., 1997. Elaboration of Multispectral Models for Heterogeneous Media: Application to the LAI. Remote Sens. Rev., 15, 223-234.
Itten, K.I. and Meyer, P., 1993. Geometric and radiometric correction of TM data of mountainous areas. IEEE Trans. Geosci. Remote Sens., 31, 764-770.

Lillesand, T.M. and Kiefer, R.W., 2000. Remote Sensing and Image Interpretation. Wiley, New York, USA. 724pp.

Ludwig, K., 2000. Die flächenverteilte Modellierung von Wasserhaushalt und Abflußbildung im Einzugsgebiet der Ammer. Münchener Geographische Abhandlungen, B32, 173pp.

Ludwig, R., Bach, H., Grüner, V. and Mauser, W., 1999. The Use of Imaging Spectrometer Data to Determine Vegetation Parameters for SVAT-Modelling. EARSEL Workshop on Imaging Spectroscopy, Zürich, Switzerland.

Mauser, W., 1989. Die Verwendung hochauflösender Satellitendaten in einem Geographischen Informationssystem zur Modellierung von Flächenverdunstung und Bodenfeuchte. Habilitationsschrift, Geowiss. Fakultät Univ. Freiburg, Freiburg, $382 \mathrm{pp}$.

Mauser, W., 1991. Modelling the spatial variability of soil-moisture and evapotranspiration with remote sensing data. Proc. Int. Symp. Remote Sensing and Water Resources, Enschede, Aug. 20-24, 1990. R. van Ackern Pub., Lingen.

Mauser, W. and Strasser, U., 1997. Modelling actual evapotranspiration of the Weser catchment with the multiscale SVAT-model PROMET. In: Landwirtschaftsökologie und Umweltforschung, B. Diekkrüger and O. Richter (Eds.): H. 25. Braunschweig, Germany. 161-164.

Mauser, W. and Schädlich, S., 1998. Modelling the spatial distribution of evapotranspiration on different scales using remote sensing data. J. Hydrol., 212-213, 250-267.

Norman, J.M., 1979. Modelling the complete crop canopy. In: Modification of the Areal Environment of Plants, B.J. Barfield, and J.J. Gerber (Eds.). Amer. Soc. Agr., 249-277.

Ranzi, R., Bacchi, B. and Grossi, G., 2003. Runoff measurements and hydrological modelling for the estimation of rainfall volumes in an Alpine basin. Quart. J. Roy. Meteorol. Soc., 129, 653-672.

Sandmeier, S.R., 1995. A physically-based radiometric correction model; correction of atmospheric and illumination effects in optical satellite data of rugged terrain. Remote Sensing Series, 26, Universität Zürich, Switzerland. 144pp.

Spanner, M.A., Pierce, L.L., Peterson, D.L. and Running, S.W., 1990. Remote sensing of temperate coniferous forest leaf area index, the influence of canopy closure, understorey vegetation and background reflectance. Int. J. Remote Sens., 11, 95-111.

Stolz, R., 1998. Die Verwendung der Fuzzy Logic Theorie zur wissensbasierten Klassifikation von Fernerkundungsdaten - Ein methodischer Ansatz zur Verbesserung von Landnutzungsklassifikationenen in mesoskaligen heterogenen Räumen, dargestellt am Einzugsgebiet der Ammer.Münchener Geographische Abhandlungen, Bnd. B 26.

Strasser, U. and Mauser, W., 2001. Modelling the spatial and temporal variations of the water balance for the Weser catchment 1965-1994. J. Hydrol., 254, 199-214. 